\title{
The welding program optimization of a \$355 steel assembly used in agricultural machinery
}

\author{
Elena-Stela Muncut ${ }^{1 *}$, Lavinia-Ioana Culda $^{1}$, Geza-Mihai Erdodi ${ }^{1}$, and Gheorghe Sima ${ }^{1}$ \\ ${ }^{1}$ University “Aurel Vlaicu” of Arad, AIITT Department, B-dul Revoluției, nr.77, 310130, Romania
}

\begin{abstract}
The paper will include the realization of a weld joint line with an $\mathrm{ABB}$ robot. The manufacturing area contains a welding device and a robot. For the robotic welding, the methods and a complete welding program will be presented. The first stage is the design of the device that can be used for manufacturing a range of comparable size pieces with similar gripping capability. There are described the axes and the way of movement, the presentation of the speeds for the rotating joints and roto-translation. CAD design of the workpiece including WPS (welding technology that contains the shape of each joint and welding parameters: welding current, electric arc voltage, welding speed and secondary parameters). The base material, the addition material, protective gases and a list of parts from the robot that require periodic changes will be presented. It is presented the CAD design of the workpiece including WPS.
\end{abstract}

\section{Introduction}

The paper will present an optimization of the welding process of steel components S355 used in the construction of agricultural machinery. The welding installation consists of an ABB welding robot and a welding station.

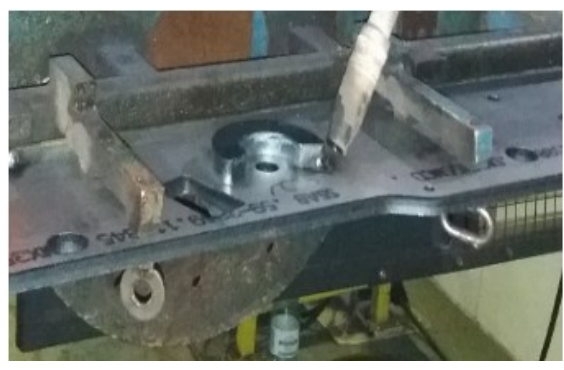

Fig. 1. a. Welding station

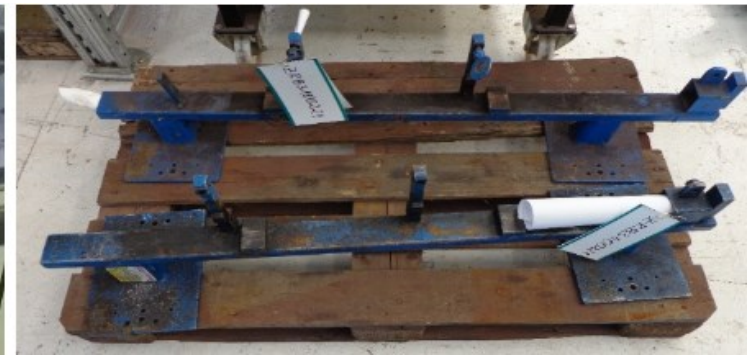

b. Welding device

The welding station has 3 rotation axes (figure 1, a), it performs a movement around the $\mathrm{z}$-axis which allows access of the two welding posts to the welding torch. The station also allows rotation on the $\mathrm{x}$ and $\mathrm{y}$ axes. The welding station allows the mounting of a welding device (figure 1, b) that is specific to each assembly that could be welded in this area.

\footnotetext{
${ }^{*}$ Corresponding author: muncutstela@yahoo.com
} 
The robot has 6 degrees of motion, given from the rotation or rotating coupling from which it is formed. The robot programming is done with the FlexPendant SDK, Figure 2[1].
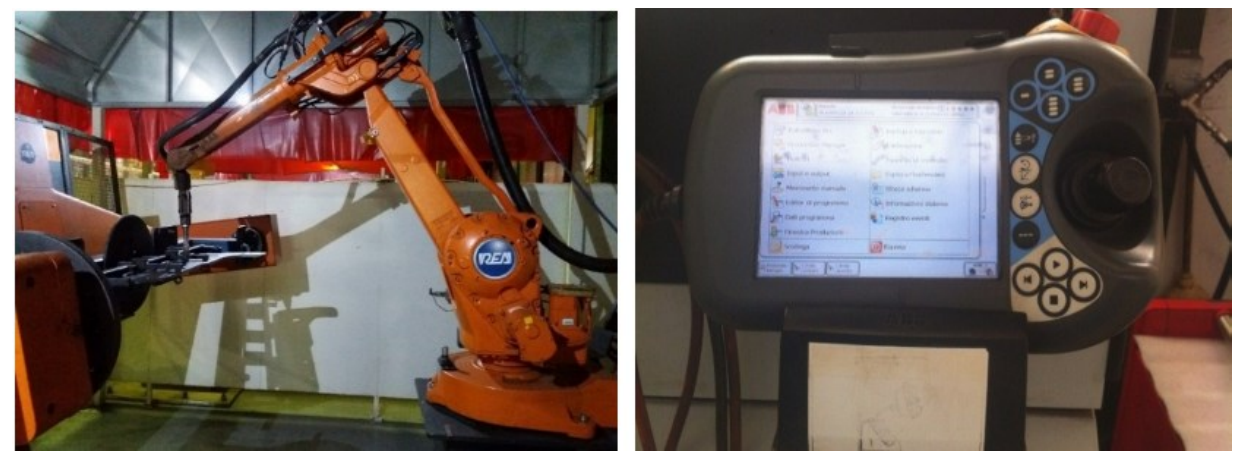

Fig. 2. The ABB robot and the SDK FlexPendant

The programming of the robot is done by learning, by the tactile sweep of the welding joint not by predetermined coordinates. The coordinates results and are recorded for the following welding commands.

\section{Motivation}

In the motherboard, a badly sized channel was cut by laser. The two pieces that are part of the considered ensemble merged by embedding. The parameters used for cutting were inappropriate resulting in a larger gap in the base plate (sole) in which the top piece (core type) is mounted. An empty semi-circle and a linear space are seen laterally, figure 3.

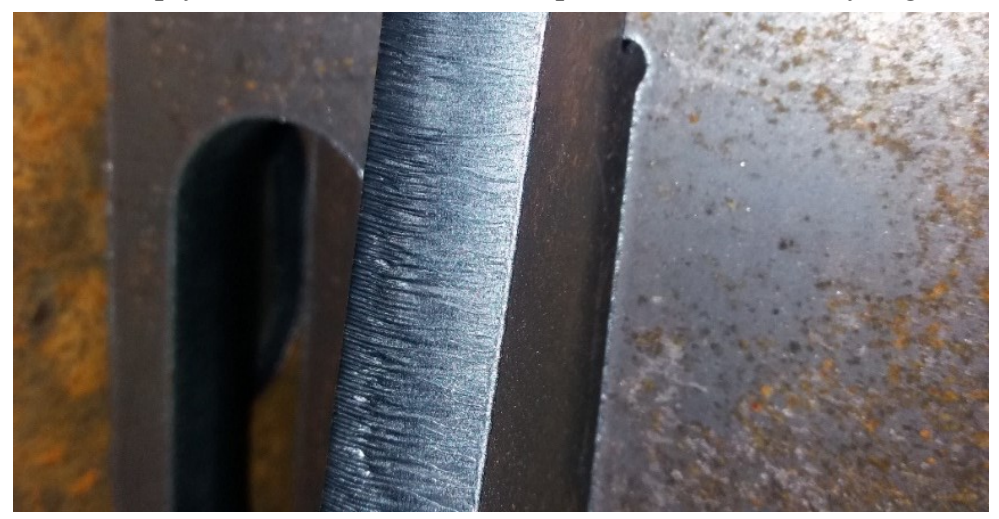

Fig. 3 Mounting part with debiting failure

For this reason, it will be used to sweep the welding head that leads to excess material. From the calculation it results that the increase of the cord from the $\mathrm{z} 5$ area is $12.5 \mathrm{~mm}^{2}$ the area of the joint at the $\mathrm{z} 6$ area will be $18 \mathrm{~mm}^{2}$, which means at $1000 \mathrm{~mm}$ length of the cord a volume from $\mathrm{z} 5 \mathrm{~V} 5=12500 \mathrm{~mm}^{3}$ and at $\mathrm{z} 6 \mathrm{~V} 6=18000 \mathrm{~mm}^{3}$. The volume difference will be $5500 \mathrm{~mm}^{3}$, that is $44 \%$ of the designer's requirement. As a result, the melted filler material enters between the two pieces in an amount greater than that established by the initial programming.

Following is the presentation of the piece after welding, where part of the molten bath has passed into the gap between the parts and thus the cord is narrower and with the greater possibility of breaking due to the tension concentrators, figure 4 . 
Remedial options:

- using a laser sensor to read the joint and transmitting to the robot the requirement to modify the parameters so that the cord remains the same geometric parameters or the locksmith after montage to manually fill the defect;

- the welding operator will be able to lower the welding speed on the defective cord portion so that the cord's z remains constant throughout its length;

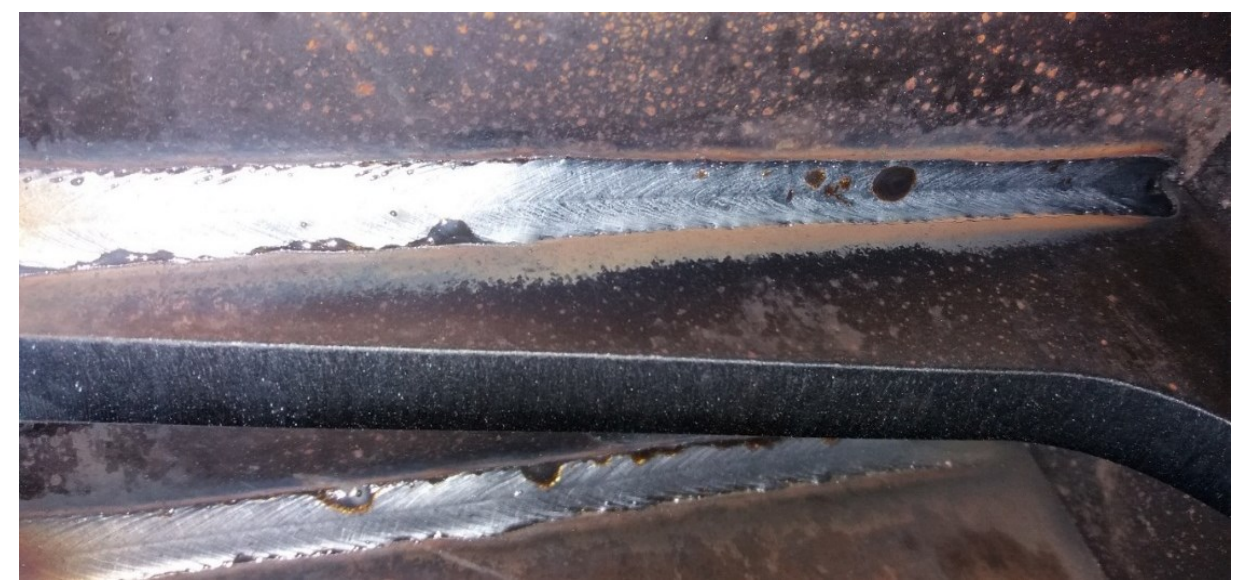

Fig. 4 Geometrically inadequate welding seam (does not have constant $\mathrm{z}$ all length)

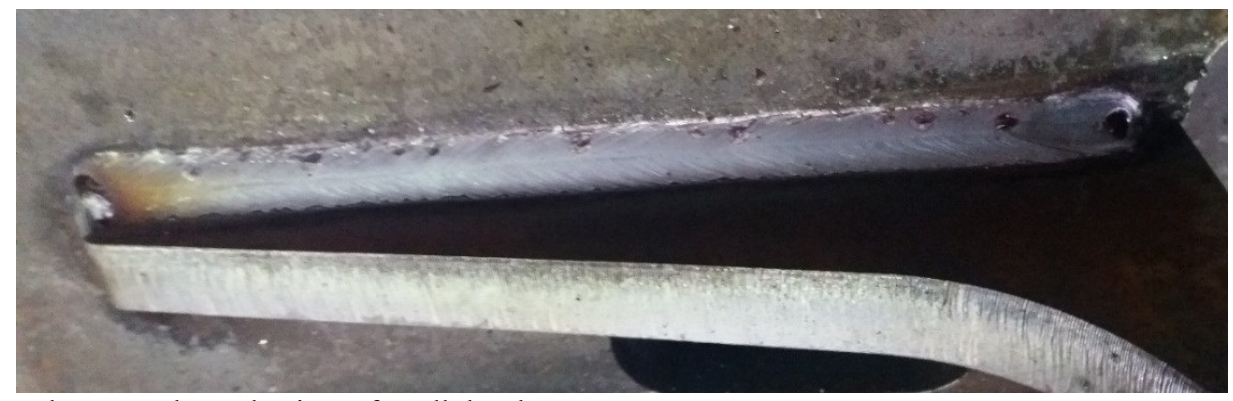

Fig. 5 The correctly made piece after all the above measures.

The motivation for these corrections (figure 5) is necessary because the piece is part of the chassis of an agricultural machinery, which raises a large amount of ground for aeration and enters up to $600 \mathrm{~mm}$ in the soil.

\section{The programming steps for welding the part}

The rotation of the welding station 1 after the x position of $\pi / 2[\mathrm{rad}]$ - the position of waiting of the assembly and programming the robot (Figure 6). At this point, the robot's zero programming is done, [2]. 

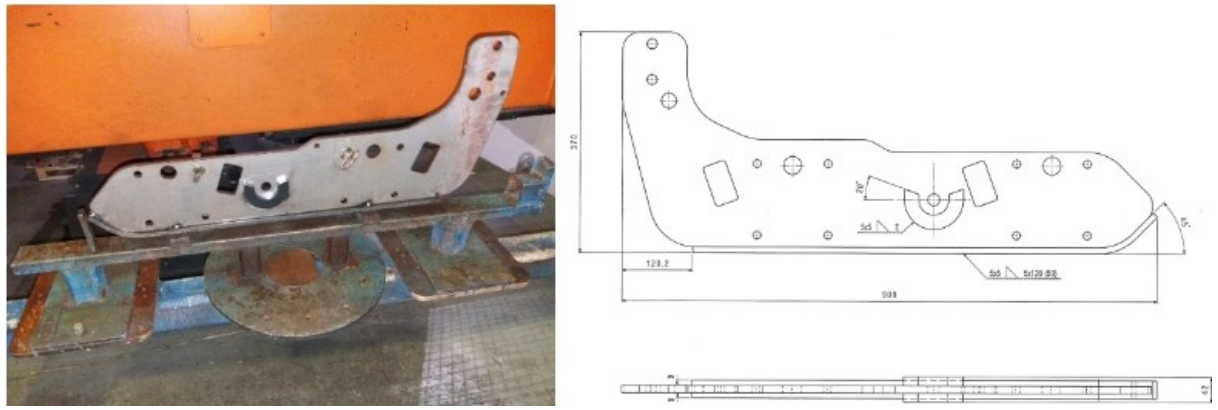

Fig. 6. The rotation of the welding station 1 after the $\pi / 2[\mathrm{rad}]$ position

The torch calibration operations and setting the 0 point of the robot follows. Position 0 and calibration of the welding torch is done by means of a special device (figure 7.a) equipped with a laser sensor:
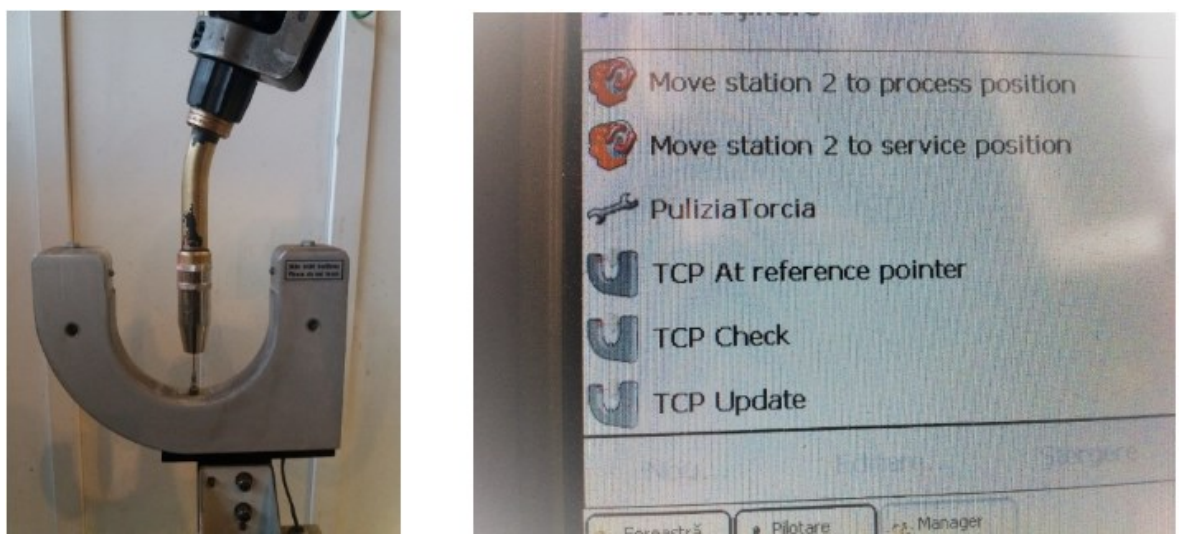

Fig. 7. a. The 0-calibration device for the robot

b. The monitor with the robot zero-point calibration

First, the wire cutter is sent to $10 \mathrm{~mm}$ from the gas nozzle and the spatters are removed (Pulizia Torcia). Prior to welding, the torch is brought to the device that spray silicone to prevent weld splashes from sticking. The head was previously manually straightened and cleaned of spatters with a miller, [3].

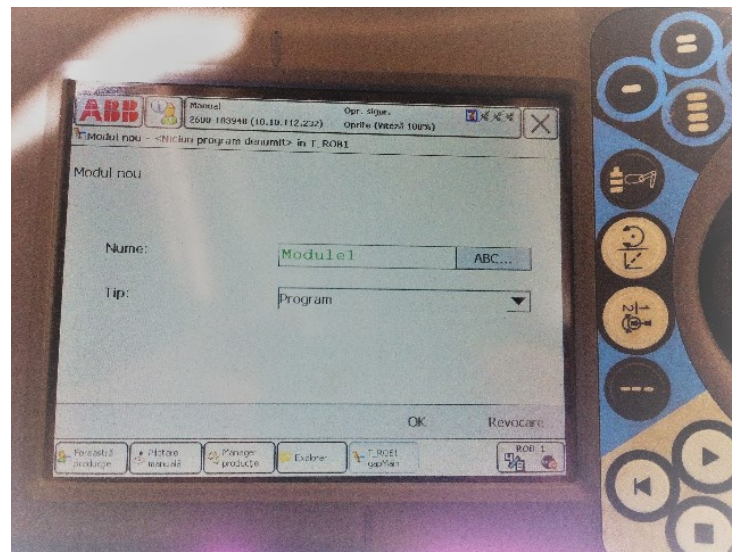

Fig. 8 Picture of the New Module and extract from the robot program 
Setting to the zero position follows with the TCP at reference pointer command, if it is not at zero, a TCP Check is performed with a laser sensor of the torch, and itself searches for the zero position of the device.

Type New Modules and the next dialog window opens. In this module you can enter a very high number of routines. Enter the part code (example R17610160 Figure 8).

Rotation along the $\mathrm{x}$-axis position $(0[\mathrm{rad}])$ - In this position (figure 9) the circular weld on the horseshoe and the corner seam between the heart and the sole are welded, [4].

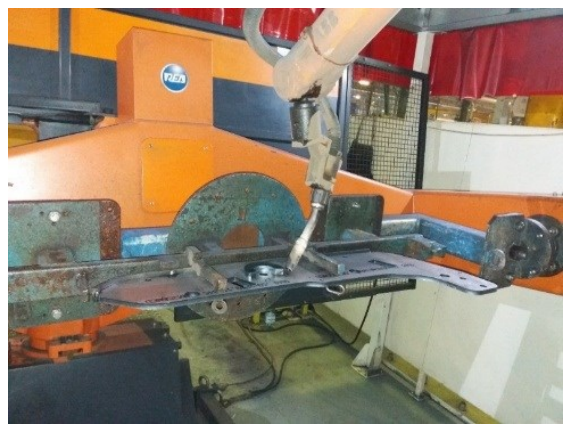

Fig.9 Rotation along the x-axis position $(0[\mathrm{rad}]$

Next, the routines are done. Routine is a repetitive and controllable welding procedure. To this operation is assigned a number from the $\mathrm{ABC}$ button and the number of the station. After this step, a dialog opens where the welding parameters (welding current, welding speed and pendulum parameters) are allocated, figure 10.
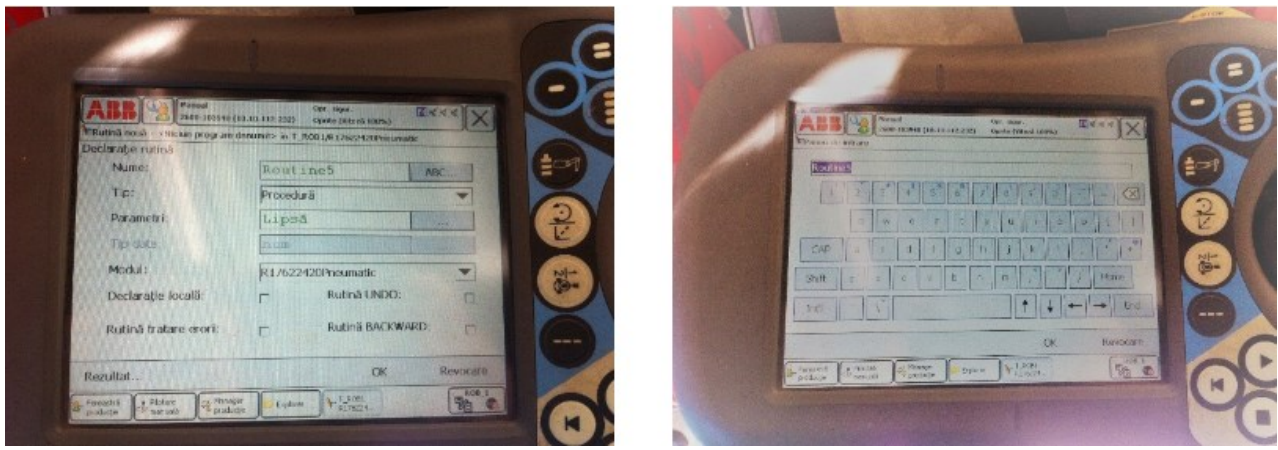

Fig. 10 Setting the routines and welding parameters

The robot reads ActStationProd - sending it into production. We started the robot reading the next move.

The following command types can be programmed: MoveL - linear motion; MoveJ movement in space from one point to another point, the robot chooses the trajectory, figure 11 ;

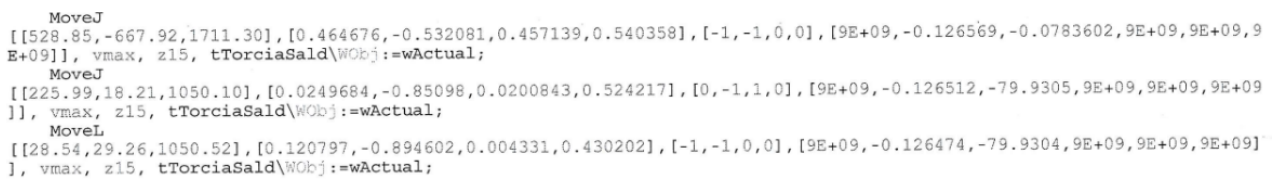

Fig.11 Program for the first welding phase

In order to make the intermittent seam it is necessary to make the following movements: 
The robot is in the standby position, doubled with the cleaning and siliconing of the torch. The programmer will move the robot so that the torch is ready for the beginning of the welding. For this purpose, two moves are made in space MoveJ, followed by MoveL, for positioning the welding head at the beginning of the joint, Figure 12.

seam1R17610160: $=[0.3,0,[8,0,0,3,0,0,0,0,0], 0,0,0,0,0,[0,0,0,0,0,0,0,0,0], 0,0.3,[8,0,-z$ $, 0,0,0], 0.2]$;

TASK PF.RS weldidata weldR $17610160:=[10,0,[8,0,-4,7.5,0,0,0,0,0],[0,0,0,0,0,0,0,0,0]]$;

Fig. 12 Data from the welding program

The introduction of the welding conditions follows (figure 13), denoted seam1R17610160 for the assembly in figure 6.
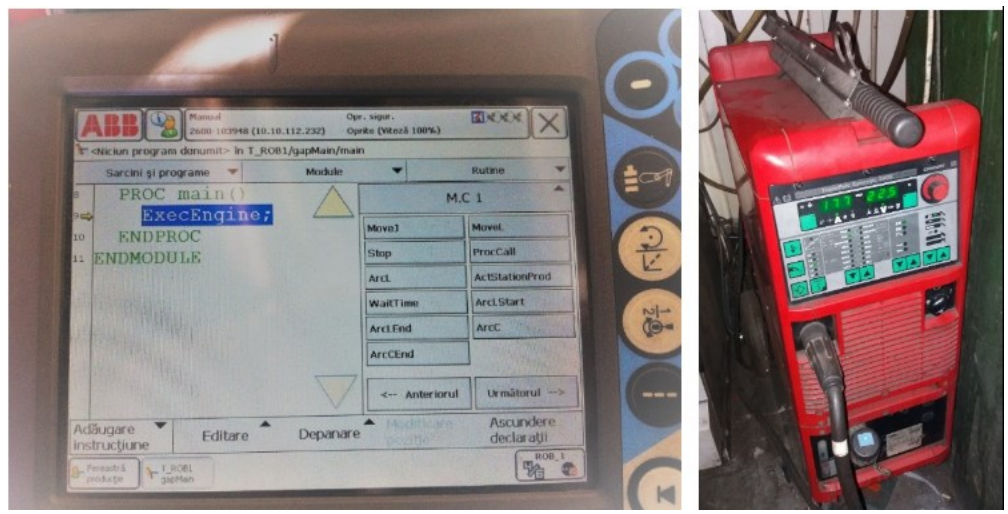

Fig.13 Introducing preliminary welding conditions for the robot and the welding source

The programmed welding parameters on the welding source: the arc source voltage selected at $22.5 \mathrm{~V}$ with a correction factor of -2 , for a $177 \mathrm{~A}$ welding current. The welding current is selected by default depending on the diameter and the material of the electrode wire, Figure 13. The gas is started by 0.3 seconds earlier (purge time) and the gas maintenance time after welding (preflow_time) is $0.2 \mathrm{sec}$. All this data was saved on the source with a number (source specification).

The welding parameters programmed on the robot are marked with weld data (weldR17610160). For this step choose the welding speed (in the case of corner joint $\mathrm{z}^{-} \mathrm{v}_{\mathrm{s}}=8$ $\mathrm{mm} / \mathrm{s}$ ) and correlate with the data selected on the source (wire feed speed, spring tension, and possible correction factors). Wire feed rate (wirefeed) is $7,5 \mathrm{~mm} / \mathrm{s}$.

The pendulum function of the welding head is marked with weavedata and the pendulum characteristics are programmed: length, height, width and frequency. The pendulum is used for a more efficient melting of the base material and for a better bond between the base material and the deposited material. This avoids overheating the base material.

\subsection{The stage of effective welding}

There are the following notations: ArcLast - the beginning of linear welding, ArcC - circular weld seam (to create an arched weld seam three points on the arc and three more on the same arc are given), ArcLend - end of the linear weld and ArcCend - at the end of circular weld seams.

If the seam is discontinuous when a gap follows, a movement is made in the lifting space of the torch, followed by moving in space at the next start of the seam and lowering to the beginning of the next seam. 
A weld seam follows with determined parameters and movement, then again, a movement is made for the gap in the discontinuous seam then we repeat the program on the other side and complete the workpiece by cleaning the torch.

The next step is to start station 2. After each program end the welding head is taken to the cleaning and silicone device (figure 14).

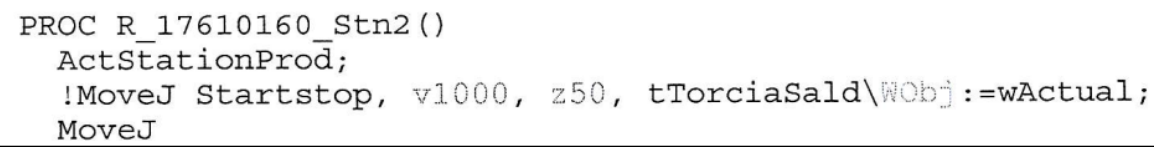

Fig. 14 Start station 2 and cleaning device

Rotation along the $\mathrm{x}$-axis position $(\pi[\mathrm{rad}]$ - Symmetric to the previous weld seam is welded: the circular weld on the horseshoe and the corner seam between the core and the sole.

We have the following welding elements: corner joint with z5 with $6 \times 80$ (50) length and for corner horseshoe $\mathrm{z} 5$ for a circular element, the cord is made all over the piece, figure 15 .

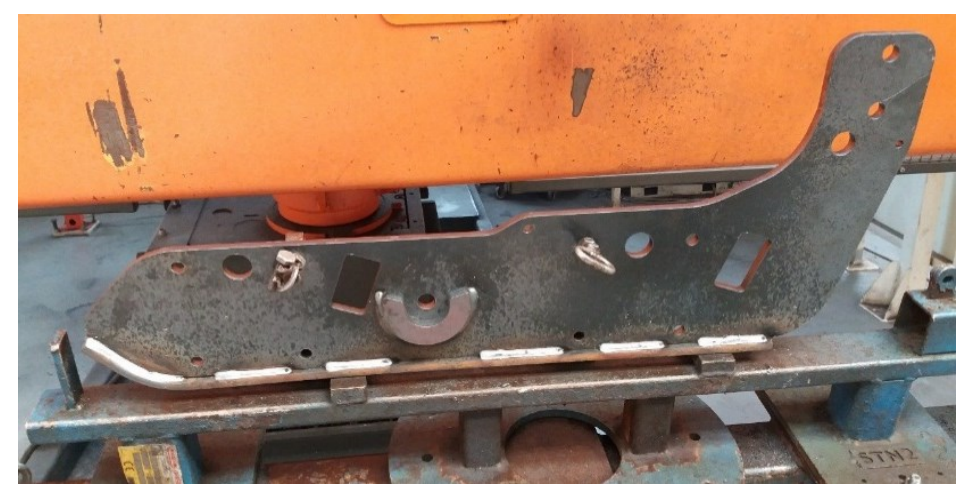

Fig. 15 The final shape of the welded joint

Initial programming was done on non-defective pieces. Later in production came a batch with preliminary processing defects of the piece.

\section{Development of comparative welding technology z5 with z6}

Thickness of base materials $s=12 \mathrm{~mm}=12 \mathrm{~mm}$ and $s_{1}=10 \mathrm{~mm}$, for corner joint.

Table 1. Welding technology

\begin{tabular}{|c|c|}
\hline \multicolumn{2}{|c|}{ The area of the joint } \\
\hline MAG z5 & $\begin{array}{c}\text { MAG z6 with pendulum with amplitude } \\
\text { of } 3 \mathrm{~mm}\end{array}$ \\
\hline$A_{z 5}=\frac{s^{2}}{2}=12,5 \mathrm{~mm}^{2}$ & $A_{z 6}=\frac{s^{2}}{2}=18 \mathrm{~mm}^{2}$ \\
\hline \multicolumn{2}{|c|}{ Welded joint area $A_{c}=(1,1 \ldots 1,4) \cdot A_{r}$} \\
\hline$A_{c}=1,2 \cdot 12,5=15 \mathrm{~mm}^{2}$ & $A_{c}=1,2 \cdot 18=21,6 \mathrm{~mm}^{2}$ \\
\hline \multicolumn{2}{|c|}{\begin{tabular}{c}
$\mathrm{d}_{\mathrm{e}}=1,2 \mathrm{~mm}$ \\
\hline
\end{tabular}} \\
\hline \multicolumn{2}{|c|}{ The diameter of the electrode is chosen according to the dimensions of the joint } \\
\hline
\end{tabular}


The number of passes is calculated using the formula: $n_{t}-1=\frac{A_{c}-A_{t 1}}{A_{u 1}}$

So, the number of passes will be $n_{t}=1$ for both joints.

$$
A_{c z 5}=1,2 \cdot 12,5=15 \mathrm{~mm}^{2} \text { and } A_{c z 6}=1,2 \cdot 18=21,6 \mathrm{~mm}^{2}
$$

\section{Choosing the welding current}

For z5 is being programmed

For z6 is being programmed

$$
I_{s z 5}=166[\mathrm{~A}]
$$

$$
I_{s z 6}=177[A]
$$

It should be noted that the calculations must be evaluated on a homologation combination, after which the value of the current will be accepted according to the structures obtained.

\begin{tabular}{|l|l|}
\hline \multicolumn{2}{|c|}{ Calculation of welding tension $U_{a}=14+0,05 \cdot I_{s}$} \\
\hline$U_{a 1}=14+0,05 \cdot 166=22,3[\mathrm{~V}]$ & $U_{a 1}=14+0,05 \cdot 177=22,85[\mathrm{~V}]$ \\
$U_{a 1}=22,4 \mathrm{~V}$ & $U_{a 1}=22,5 \mathrm{~V}$ \\
\hline
\end{tabular}

Calculation of welding speed $v_{s}=\frac{k \cdot v_{s}}{K} \mathrm{~cm} / \mathrm{min}, k \cdot v_{s}=192$ according [5]

Welding speed for

$A_{t z 5}=1,2 \cdot 12,5=15 \mathrm{~mm}^{2}$

$A_{s}=1,13-$ section of the wire section

where $K_{1}=\frac{A_{t z 5}}{A_{s}}=13,27$

$v_{s} z 5=\frac{k \cdot v_{s}}{K_{1}}=\frac{192}{13,27}=14,46 \mathrm{~cm} / \mathrm{min}$

$v_{s} z 5=0,241 \mathrm{~cm} / \mathrm{s}$
Welding speed for

$A_{t z 6}=1,2 \cdot 18=21,6 \mathrm{~mm}^{2}$

$A_{s}=1,13$ - section of the wire section

where $K_{1}=\frac{A_{t z 6}}{A_{s}}=19,11$

$v_{s} z 6=\frac{k \cdot v_{s}}{K_{1}}=\frac{192}{19,11}=10,04 \mathrm{~cm} / \min$

$v_{s} z 6=0,167 \mathrm{~cm} / \mathrm{s}$

Drop with $30 \%$ of the welding speed

$$
\begin{aligned}
& \text { Calculation of linear energy } E_{l}=\frac{\eta \cdot I_{s} \cdot U_{a}}{v_{s}} \\
& E_{l 1}=\frac{\eta \cdot I_{s 1} \cdot U_{a 1}}{v_{s 1}}=\frac{0,85 \cdot 166 \cdot 22,4}{0,241}= \\
& =13114,68[\mathrm{~J} / \mathrm{cm}] \\
& \begin{array}{l}
E_{l 1}=\frac{\eta \cdot I_{s 1} \cdot U_{a 1}}{v_{s 1}}=\frac{0,85 \cdot 177 \cdot 22,5}{0,167}= \\
=20270,20[\mathrm{~J} / \mathrm{cm}]
\end{array}
\end{aligned}
$$

Determination of preheating temperature is not required because the welded material has the equivalent carbon CEN below $0,2 \%$ according [6]

\section{Calculation of secondary and tertiary welding parameters}

$$
\begin{gathered}
v_{a z 5}=8 \mathrm{~mm} / \mathrm{s} \\
l_{l}=12 \mathrm{~mm} \\
\alpha=45^{0}
\end{gathered}
$$

Gas flow $\mathrm{Q}=15-18$ [1/min]

$$
\begin{gathered}
v_{a z 6}=8,5 \mathrm{~mm} / \mathrm{s} \\
l_{l}=12 \mathrm{~mm} \\
\alpha=45^{\circ}
\end{gathered}
$$

Gas flow $\mathrm{Q}=15-18[1 / \mathrm{min}]$

Calculating the cost of adding material resulting from the difference of the two joins

$A_{c}=A_{t z 6}-A_{t z 5}=21,6-15=6,6\left[\mathrm{~mm}^{2}\right]$ the difference between the two areas of the joins 


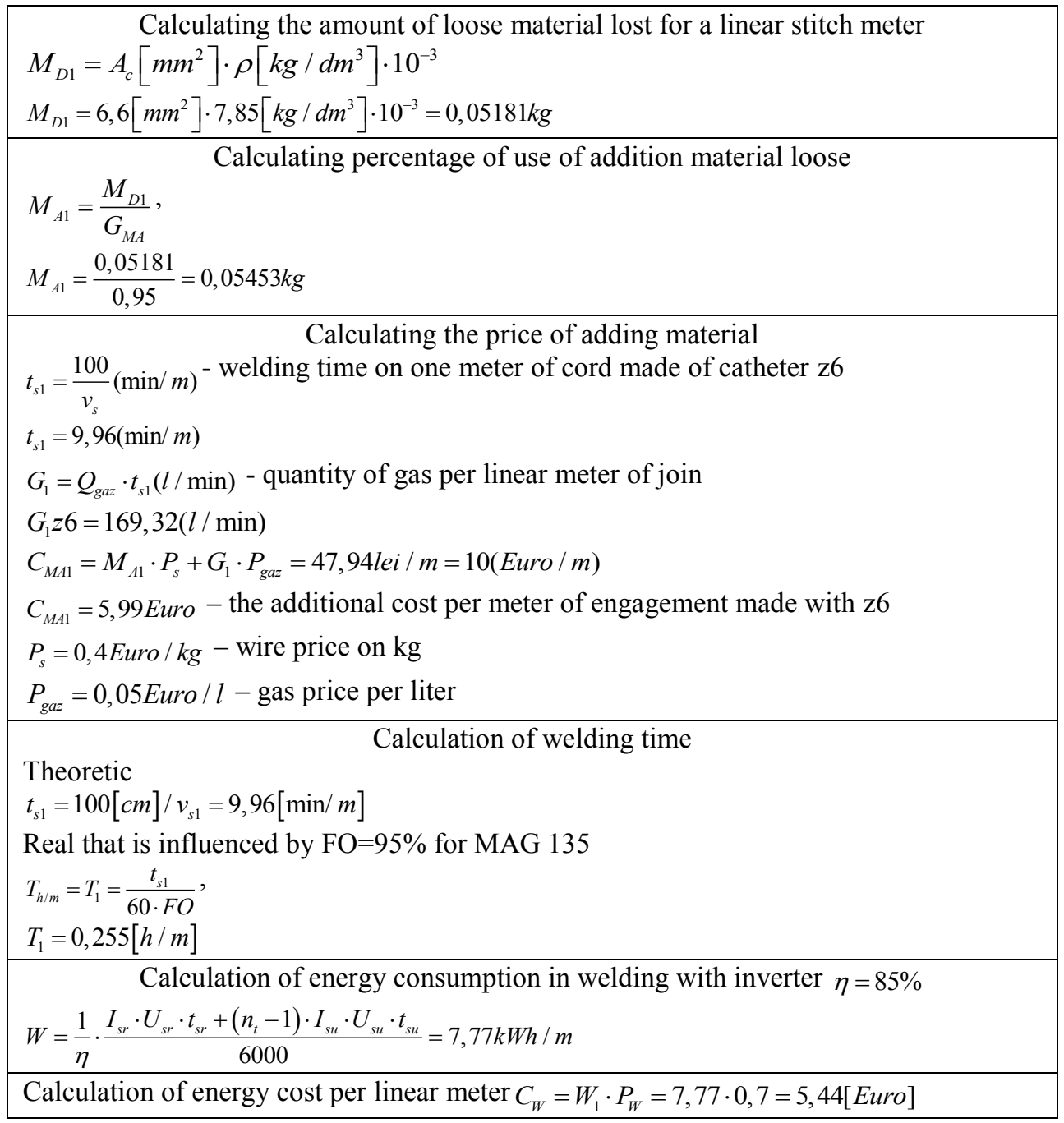

\section{Conclusions}

Making welded joints with robots is more and more prevalent. But for this it is necessary to process the joints with low tolerance.

The presented study shows that engineers with lower welding skills can learn programming if they receive enough information or sufficient visual tools. But programming a robot performing a weld at the stage of approval shall take into account the structural changes occurring in HAZ not only defects that appears because of an improper joint.

In the study, there were defects due to the wrong dimensions of the parts obtained by machining and the welding operator's attempt to correct the program, without taking into account the structural changes.

The mounting stage of an assembly should be as precise as possible and the preassembled cords should be of a length specified by the designer.

It can be seen that a processing defect can lead to an increase of consumption by $44 \%$ of the additive material, accompanied by additional energy consumption, protective gases, a $30 \%$ reduction in welding speed, and the biggest problem is the introduction of some fissure. 
The price per $1 \mathrm{~m}$ linear welding has increased by 16,0 Euro only for materials and energy consumption.

In the company where the problem was studied, one of cause of these problems is the lack of skilled workers in both welding and machining.

\section{Reference}

1. Operating manual RobotStudio, Document ID: 3HAC032104-001 Revision: F, (2008-2011);

2. Yuan Li; You Fu Li, Qing Lin Wang;De Xu;Min Tan, Measurement and Defect Detection of the Weld Bead Based on Online Vision Inspection, IEEE, Volume:59 Issue:7, 2016;

3. D.O. Glavan, T. Babanatsas, M. Borzan, I. Radu, R.M. Babanatis Merce, KOD 2018 IOP Conference Series: Materials Science and Engineering, 393 (2018);

4. D.O. Glavan, T. Babanatsas, MATEC Web of Conferences, 121 (2018);

5. P. Papcuna, J. Jadlovskýa, Procedia Engineering, 48 (2012);

6. A. Oddie, P. Hazlewood, S. Blakeway, A. Whitfield, Innovation in Teaching and Learning in Information and Computer Sciences, 9:2, 1-11 (2010);

7. D. Schreiber, L. Cambrini, J. Biber, B. Sardy, The International Journal of Advanced Manufacturing Technology, 42, pp 497-504 (2009) 